Portland State University

PDXScholar

Chemistry Faculty Publications and

Presentations

Chemistry

6-2019

\title{
E-Cigarette Chemistry and Analytical Detection
}

Robert M. Strongin

Portland State University, strongin@pdx.edu

Follow this and additional works at: https://pdxscholar.library.pdx.edu/chem_fac

Part of the Chemistry Commons, and the Other Chemicals and Drugs Commons

Let us know how access to this document benefits you.

Citation Details

Strongin, R. M. (2019). E-Cigarette chemistry and analytical detection. Annual Review of Analytical Chemistry, 12.

This Pre-Print is brought to you for free and open access. It has been accepted for inclusion in Chemistry Faculty Publications and Presentations by an authorized administrator of PDXScholar. Please contact us if we can make this document more accessible: pdxscholar@pdx.edu. 


\title{
E-Cigarette Chemistry and Analytical Detection
}

\author{
Robert M. Strongin \\ Department of Chemistry, Portland State University, Portland, Oregon 97201, USA;
}

\begin{abstract}
The study of e-cigarette aerosol properties can inform public health while longer-term epidemiological investigations are ongoing. The determination of aerosol levels of known toxins, as well as of molecules with unknown inhalation toxicity profiles, affords specific information for estimating the risks of e-cigarettes and for uncovering areas that should be prioritized for further investigation.
\end{abstract}

\section{Keywords}

electronic cigarette; aerosol; harm reduction; tobacco; propylene glycol; glycerol; flavoring

\section{INTRODUCTION}

E-cigarettes are the basis of a multibillion dollar global industry. Their introduction as commercial products in 2006-2007 created an ongoing debate that has polarized the public health community. Their long-term health effects are unknown. There is a well-documented latency period for tobacco-related disease that spans a minimum of 25 years (1). It will thus be at least two decades until definitive findings from long-term studies on e-cigarette use are available. Meanwhile, investigations of e-cigarette aerosol chemistry can provide information needed for evidence-based decisions and policies.

\section{Types of E-Cigarettes}

The term electronic cigarette refers to a variety of evolving devices that are designed to deliver nicotine and/or other substances under aerosolization conditions without combustion and tar generation. E-cigarettes consist of a mouthpiece, a tank for e-liquid, and an atomizer. The atomizer has a wicking material that delivers liquid to a battery-powered heating coil. The e-liquid, upon heating, forms an aerosol inhaled by the user (known as a vaper). Most eliquids contain the organic solvents propylene glycol (PG) and glycerol (GL), along with nicotine, flavoring molecules, and/or various other additives.

There are currently four generations of e-cigarettes. The first generation models, e.g., the cig-alike devices, bear the greatest physical resemblance to traditional cigarettes. They

strongin@pdx.edu. DISCLOSURE STATEMENT

The author is not aware of any affiliations, memberships, funding, or financial holdings that might be perceived as affecting the objectivity of this review. 
afford the least amount of user control over heating and other variables, though newer models can come with refillable cartridges. Nicotine delivery is not as efficient as compared to newer devices. Second generation models are larger, enable voltage adjustment by users (ca. 3.0-6.0 V), and have higher-capacity lithium-ion rechargeable batteries. Third generation e-cigarettes have larger batteries that are removable and charged externally. The tanks contain more e-liquid that is heated at higher temperatures and afford user control over both voltage and wattage. Vapers can also modify (rebuild) third generation e-cigarette atomizers. These models often contain sub-ohm resistance heating coils that aid users in generating relatively large aerosol volumes. Fourth generation e-cigarettes enable control over the temperature of the heating coil. Later generation models can be used at much higher power levels (e.g., >200 W) as compared to most earlier devices (ca. <15 W).

The brand with the largest e-cigarette US market share ( 50\% as of 2017 and growing) is JUUL (2). JUUL e-cigarettes are notable for their popularity among teens (3). These devices do not fall into any of the four generation classifications, but rather are part of a new genre called pod-mods (Figure 1). JUULs are like first generation devices in that they do not afford control over power levels or customization of device components; users only choose among the available flavored liquids. What sets JUULs apart is their relatively small size and sleek, striking resemblance to USB flash drives (Figure 1). They deliver higher levels of nicotine (as nicotine salt) compared to the vast majority of other brands. One cartridge (a JUUL pod) contains $0.7 \mathrm{~mL}$ of nicotine, or nearly $60 \mathrm{mg} / \mathrm{mL}$, affording a nicotine dose similar to that of a pack of traditional cigarettes (3).

\section{The Harm Reduction Principle and E-Cigarettes}

There are approximately 600 ingredients in traditional cigarette tobacco that produce 7,000 chemicals upon combustion, including numerous toxins. "People smoke for the nicotine but die from the tar" was famously stated by Russell in his 1976 manuscript describing the rationale for low-and medium-tar cigarettes (4, p. 1431). Since e-cigarettes avoid combustion and tar generation, Russell's statement embodies the primary justification used by e-cigarette proponents to market them as harm reduction products. Big tobacco, which is currently heavily invested in e-cigarettes, has a documented history of using harm reduction as an opportunistic means to influence and undermine tobacco control policies (5).

Known toxins present in e-cigarette aerosols.-Paracelsus, nearly 500 years prior to Russell, wrote: "What is there that is not poison? All things are poison and nothing is without poison. Solely the dose determines that a thing is not a poison" (6, p. 126). This dictum was a precursor to modern dose threshold concepts such as the no-adverse effect level (NOAEL), the highest tested dose or concentration of a substance at which no adverse effect is found (6).

E-cigarette emission levels of known inhalation toxins such as the carbonyls acrolein, acetaldehyde, and formaldehyde, have been reported over relatively wide ranges. According to Bhatnagar (7), even at the low end of the reported ranges, toxin levels in e-cigarette aerosols can promote cardiovascular harm. Other toxins found in e-cigarette aerosols include heavy metals, nanoparticles, plasticizers, and flame retardants (8-10). 
Unknown potential toxins present in e-cigarette aerosols.-E-liquids contain solvents and other molecules that are not present in significant amounts, or at all, in traditional cigarettes. The Flavor and Extract Manufacturers Association warns that the GRAS designation is based on ingestion and that the effects of inhaled e-cigarette flavoring chemicals are generally unknown (11). This includes the organic solvents PG and GL, as well as most additives. The inhalation exposure route circumvents the first-pass metabolic effects of the stomach and liver, thereby enabling more direct delivery of inhaled chemicals to circulation.

Korzun et al. (12) have found that newer generation devices designed to deliver larger aerosol clouds via enhanced airflow, lower resistance heating coils, and direct-to-lung vaping (see sidebar titled Preferred Methods of Vaping), can readily expose users to inhalation levels of PG that are in range of the daily GRAS exposure thresholds for PG as a food ingredient. In a study of dozens of refill fluids encompassing a broad range of flavors, including buttery/creamy, minty, sweet, candy, fruit, tobacco, and cinnamon/spiced, Behar et al. (13) found that approximately one-third were cytotoxic to human pulmonary fibroblasts and stem cells. Fetterman and coworkers (14) found that e-cigarette flavorings increased inflammation and impaired nitric oxide (NO) production in endothelial cells, events that have been linked to the development of cardiovascular disease.

Sassano and coworkers (15) developed a high-throughput screen to efficiently determine the cytotoxicity of large numbers of e-liquid samples. They found that the PG/GL solvents adversely affected cell viability. A larger total number of chemical ingredients in e-liquids correlated with enhanced cytotoxicity. Vanillin and cinnamaldehyde were specific flavoring molecules associated with relatively high toxicity levels. An additional contribution of this study was the creation of an open-access, searchable website resource https:// www.eliquidinfo.org.

\section{E-Cigarette Toxins and Adolescents}

Each side of the e-cigarette harm reduction debate is extensively described in articles by Glantz \& Bareham (16) and Abrams et al. (17) in a recent volume of the Annual Review of Public Health. One point of agreement among public health experts is that e-cigarettes should not be used by minors. A consequence of the aggressive application of the harm reduction principle to date is an environment of relatively easy access to e-cigarette products. Advertising, device designs, and flavors that appeal to children and teens are prevalent. On September 12, 2018, the commissioner of the US Food and Drug Administration, Dr. Scott Gottlieb, declared youth vaping an epidemic (18). Current usage of e-cigarettes was reported in 2017 by $11.7 \%$ of all US high school students and $3.3 \%$ of all US middle school students (19).

It is well known that nicotine exposure during adolescence harms the brain and other developing organs. The cumulative harm can be significant if addiction and chronic use of tobacco products start relatively early in life (20). In a study of chemical toxicant biomarkers in adolescents (average age $=16.4$ years), Rubinstein and coworkers (21) found that the urinary excretion of metabolites of benzene, ethylene oxide, acrylonitrile, acrolein, and acrylamide was significantly higher in dual users, compared to e-cigarette-only users. 
Metabolites of acrylonitrile, acrolein, propylene oxide, acrylamide, and crotonaldehyde were also elevated in e-cigarette-only users compared to control groups.

E-cigarettes contain fewer total toxins compared to traditional cigarettes, supporting the current case for harm reduction. Although the emphasis to date on comparing the relative health effects of e-cigarettes to traditional cigarettes is clearly necessary, downplaying the chemistry and health impacts unique to e-cigarettes is not only limiting but also irrelevant to the large number of young people who are vaping without having ever smoked a cigarette (22). Investigations of e-cigarette chemical constituents and properties clearly show that ecigarettes are not harmless. Unbiased research on e-cigarette aerosol chemistry has afforded knowledge in contrast to industry marketing claims, such as e-cigarettes produce "harmless water vapor" $(23,24)$.

\section{THE MAJOR CHALLENGES OF E-CIGARETTE ANALYTICAL RESEARCH}

It is well known that chemical reactions occur during the heating and aerosolization of eliquids and that this consistently leads, for example, to the formation of toxins, including formaldehyde, acetaldehyde, and acrolein. The chemistry of GL and PG has been studied by chemists for more than a century (see sidebar titled Glycerol, Propylene Glycol, and The History of Chemistry).

The main reaction mechanisms are oxidation and dehydration and have been described in detail by Jensen et al. (25). This group has published a useful library of the ${ }^{1} \mathrm{H}$ NMR spectra of more than a dozen major PG and GL thermal degradation products found in e-cigarette aerosol mixtures (25) (Figure 2). The major proposed reaction pathways are shown in Figures 3 and 4 .

Although the identity of many of the specific aerosol toxins reported has not generally been questioned, a major issue in the field is significant interlaboratory variability in the reported levels of e-cigarette emissions. For example, results between studies measuring formaldehyde levels produced from second generation, top-coil devices have varied over a range of five orders of magnitude, from below the detection limit to $97 \mu \mathrm{g} / \mathrm{puff}$ (27).

Amain issue is the lack of validated standardized sampling and analytical methods. For example, Eddingsaas and coworkers (28) found that common emission sampling methods such as filter pads or impingers, when used in isolation, underestimate levels or do not identify specific aerosol compounds. They recommend an investigation of not only filter pads and impingers but also thermal desorption tubes and solvent extraction resins in order to obtain more complete and robust aerosol profiles. A 2016 review by Bansal \& Kim (29) highlighted the diversity in sampling and analytical methods used in e-cigarette research, as summarized in Figures 5 and 6, respectively

The variability in sampling and analytical protocols across different laboratories is exacerbated by additional confounding factors. These include the ever-increasing diversity of e-cigarette models and design features and the thousands of e-liquid formulations. The following sections focus on recent progress made by researchers in addressing these and related challenges. 


\section{The Rapidly Evolving E-Cigarette Landscape}

In order to study the increasing heterogeneity of e-cigarettes, Malek and coworkers (30) reported a systematic tracking system. They tested it by comparing devices used in 2014 versus 2016. They used social media and analytics tools such as Alexa for website rankings, Google and Yahoo search results, as well as Facebook, Twitter, and YouTube channel metrics to rank the popularity of each e-cigarette brand. The researchers purchased products from the highest-ranked 10 brands that had the greatest number of website product reviews or those that were recommended as starter products. Only 8 of the 23 most popular brands in 2014 remained as popular in 2016 . The devices were disassembled to assess parameters including heating coil characteristics, wick lengths, air tube diameters, electrical connections, and filling materials. Battery voltage, coil resistance and pressure drop, e-liquid $\mathrm{pH}$, nicotine concentration, $\mathrm{PG} / \mathrm{GL}$ ratio, and water content were monitored. They used their own previously validated mathematical model to compute nicotine emissions. A main outcome was that devices were found to differ in regard to heating coil dimensions and orientation relative to airflow, coil location, pressure drop, and other variables, resulting in $>50 \%$ differences in nicotine emissions for a given power setting and e-liquid (30).

Zhao and colleagues $(31,32)$ took a different approach to dealing with device heterogeneity by creating an exposure generation platform to systematically correlate device variations and aerosol properties. Brand type/generation (disposable, prefilled, and refillable tanks), flavor additives, user topography, and power levels were investigated. Particle concentrations were dependent on device generation. They were in the range of millions of particles $/ \mathrm{cm}^{3}$ with a peak at approximately $200 \mathrm{~nm}$, similar to traditional cigarettes. Toxins such as benzene and toluene were detected and varied according to device type and the other parameters studied. For example, compared to tobacco flavor, menthol generated 330\% more benzene and 120\% more toluene. Fruit flavor generated $240 \%$ more benzene and $30 \%$ less toluene than tobacco flavor (31). Zhao and coworkers also found that varying, elevated levels of reactive oxygen species could be generated in e-cigarette aerosols as a function of e-cigarette device design, power, flavors, and puffing topography (32). Despite their different approaches, the studies by the Zhao and Malek groups confirm the influence of evolving device design features as well as e-liquid ingredients in modulating aerosol emission levels.

\section{Characterizing the Flavoring Molecules Found in E-Liquid Formulations}

There are thousands of e-liquid flavor formulations available. Behar et al. (13) used gas chromatography-mass spectrometry (GC-MS) and a ranking strategy to identify the most prevalent flavoring molecules in a library of commercial e-liquids. Six compounds were found at both relatively high concentrations of $>1 \mathrm{mg} / \mathrm{ml}$ and prevalence in $41-80 \%$ of the products. These included menthone, $p$-anisaldehyde, menthol, cinnamaldehyde, vanillin, and ethyl maltol. Transfer efficiencies from e-liquid to aerosols were high, except in the case of ethyl maltol (58-62\%), showing that aerosols can deliver high concentrations of flavoring compounds. Most of the refill fluids that exhibited low cytotoxicity had total flavoring chemical concentrations of $<5 \mathrm{mg} / \mathrm{mL}$, supporting the hypothesis that toxicity is correlated with higher concentrations of flavor chemicals (13). 


\section{Heating Coils and Wicking Efficiency}

It is well known that higher levels of toxic thermal degradation by-products can form as a function of higher temperatures for a given device. Wicking efficiency and heat transfer are the main determining factors in levels of degradant production at a given temperature. Poor wicking efficiency can lead to a dry coil and overheated e-liquid (dry puff). Not allowing sufficient time for cooling between puffs hampers wicking efficiency and promotes the thermal degradation of e-liquid components. Other factors inhibiting proper wicking include high e-liquid viscosity and aged or poorer quality manufactured coils. For example, Jensen and coworkers (25) reported that the use of replacement heating coils of the same design and from the same manufacturer, identical in appearance and packaged together, led to wide variability in the abundance and profile of aerosol decomposition products.

Gillman et al. (33) found broad variability in toxic carbonyl production while investigating various devices. They observed an inverse relationship between the efficiency of e-liquid consumption and toxic carbonyl aerosol levels. This is consistent with efficient wicking and aerosolization enabling more effective delivery and less thermal degradation and carbonyl production. Vreeke and coworkers (34) found that the stability of the wick temperature, as one measure of wicking efficiency during aerosolization, could serve as a predictor of the degree of PG and GL degradation. Talih et al. (35) determined that heating coil surface area was a better predictor of carbonyl emissions than power setting alone. In a recent publication that also sheds light on the origins of the variability in reports of e-cigarette carbonyl emission levels, Chen and coworkers (27) reported on the association of coil temperature, eliquid fill levels, coil resistance, and voltage. Their main findings included the observation that temperature, when determined using an infrared camera rather than with a thermocouple, is not evenly distributed along the length of a coil (this could lead to localized hot spots causing thermal degradation) and, under the most user-relevant wick/coil wetness conditions, there are wide variations in coil temperatures that can afford inconsistent carbonyl levels.

The influence of conflict-of-interest in e-cigarette publications on the favorable reporting of results by industry-supported researchers has been previously studied (36). Some staunch ecigarette proponents insist that all published instances of elevated levels of e-cigarettederived toxic carbonyls (e.g., above workplace or related threshold exposure values) are irrelevant to actual usage. The rationale is that elevated carbonyls occur only under dry puff conditions and, thus, vapers would be able to efficiently sensorially detect and self-regulate aerosol carbonyl levels when above safe thresholds (37). This claim is based largely on the conclusions of three investigations, involving experienced vaper human cohorts consisting of just two (both of whom were members of the research team) (38), seven (39), and twenty-six users (40). The reader is urged to objectively evaluate these latter studies as well as the published concerns about the methods and conclusions expressed therein (41-43). Importantly, a recent investigation shows that carbonyl formation can be catalyzed by ecigarette metal heating coil materials, enabling carbonyl formation at coil temperatures far below those associated with the dry puff phenomenon (44). Chen et al.'s (27) study of coil temperature and wicking variables also resulted in the conclusion that concerning levels of formaldehyde in frequent e-cigarette users can be produced at relatively low power levels, 
and within the range of operating temperatures observed by human subjects to afford sensorially pleasant conditions, i.e., not under dry-puff conditions.

There have been several methods reported to prevent the dry puff phenomenon during aerosol production and analysis in the laboratory. Power levels should be set to within manufacturers' recommended ranges. Determination of the components of aerosols generated from a single, iso lated puff are possible using nuclear magnetic resonance (NMR) spectroscopy, a nondestructive technique that also enables identification of relatively less stable aerosol products (25). Evidence of burnt e-liquid can often be readily observed, for example, by wicking material discoloration, coil discoloration, or a burnt sample odor (12).

\section{E-Cigarette Flavoring Molecule Chemistry}

E-liquid flavoring molecules have additionally been shown to promote elevated levels of toxic carbonyls (generally) $(45,46)$ or furans (e.g., furfurals from the heating of sugars) (47). Vreeke and coworkers (48) showed that not all flavoring molecules break down directly into the main byproducts observed. For example, ${ }^{13} \mathrm{C}$-labeled triacetin was shown by NMR to degrade to acetic acid that subsequently catalyzed the degradation of PG and GL to acrolein, acetaldehyde, and formaldehyde hemiacetals. Khlystov \& Samburova (45) have also shown that the addition of flavoring molecules to e-liquids results in elevated levels of toxic carbonyls in e-cigarette aerosols. Their findings were challenged by e-cigarette proponents (49); however, the researchers followed up their study by finding elevated levels of toxic aldehydes in the exhaled breath of a cohort of e-cigarette users (50). Moreover, $\mathrm{Qu}$ and coworkers (51) found that carbonyl emission factors increased linearly with flavorant base content. They calculated a 40-year cancer risk due to formaldehyde (a 70-kg e-cigarette

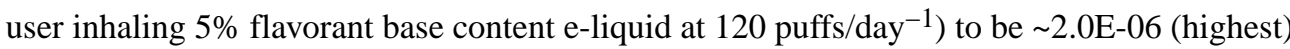
compared to $\sim 1.0 \mathrm{E}-06$ for PG and GL solvents alone. Their results confirmed prior findings by Khlystov \& Samburova (45) and Klager et al. (46) showing that flavoring molecule degradation significantly enhances toxic carbonyl formation. Bitzer et al. (52) investigated free radical generation from 49 commercial e-liquid flavors. They determined that nearly one-half of the flavors modulated free radical production, with most promoting radical generation in a concentration-dependent manner.

\section{Gas- and Particle-Phase Toxin Partitioning and Evaluating Nicotine Protonation}

An e-cigarette aerosol is a collection of liquid particles suspended in a gas phase. Volatile and semivolatile aerosol components partition into each of the phases to varying degrees. Understanding the partitioning properties of molecules present in e-cigarette aerosols enables one to make informed choices of sampling and analytical methods, depending on their suitability for analysis of analytes in the phase(s) of interest. Importantly, it aids predictions of deposition patterns of specific aerosol components in the respiratory system.

The gas- and particle-phases of e-cigarette aerosols.-Pankow (53) has applied the principles of gas/particle tobacco smoke partitioning to e-cigarette aerosols. He predicted particle/gas distributions as a function of the mass concentration of the aerosol droplets $\left(\mu \mathrm{g} / \mathrm{m}^{3}\right)$, the composition of the droplets, temperature, and the vapor pressure of each compound. Even at the highest total particulate matter levels for e-cigarette aerosols, 
formaldehyde as the carbonyl form, $\mathrm{CH}_{2} \mathrm{O}$, will partition mainly into the gas phase, whereas formaldehyde hemiacetals and methane diol (formaldehyde hydrate) will partition into the particulate phase, even at the lowest total particulate matter levels (53).

Particle size distribution.-Aerosol particle size distributions determine the specific respiratory tract deposition efficiency and delivery of particle-phase compounds. Oldham et al. (54), for example, have recently described the well-known challenges inherent in ecigarette particle size measurements that have led to inconsistent interlaboratory measurements. Issues include the dynamic nature of e-cigarette aerosols, inconsistent dilution volumes, and the limitations inherent in optical and inertial methods. Real-time measurements of aerosol size evolution during puff development have been examined using a high-resolution aerosol differential mobility spectrometer (55). The e-cigarette aerosol size distributions were bimodal, with both submicron particles and nanoparticles found. The authors noted that the greater surface area of nanoparticles could render them more bioactive than submicron particles with similar chemical properties.

Nicotine.-There have been numerous investigations of e-cigarette nicotine $(56,57)$. Duell and coworkers (58) have developed an accurate NMR-based method to determine the fraction of free-base nicotine in e-liquids (Figure 7), without introducing solvents that perturb previous measurements.

The rapid emergence of high-nicotine-content JUULs has generated interest in determining the protonation state of the nicotine contained in the JUUL pods. Mono-protonated and freebase nicotine are its major forms in equilibrium. Free-base nicotine can partition into both the gas and particle phases, whereas protonated nicotine will be delivered primarily to the lungs via the particle phase. Particle-phase, protonated nicotine has been linked to nicotine addiction. Not only do JUUL pods contain far greater levels of nicotine than nearly all ecigarettes, but they also have an extremely low proportion of free-base to protonated nicotine Figure 8.

Importantly, protonated nicotine is not nearly as harsh as free-base nicotine, and is thus a likely reason that many teens prefer JUULs and do not realize that JUULs even contain nicotine (59). The combination of commercial flavors and extreme levels of nicotine in the form with the least harshness embodies a potentially powerful formula for creating and sustaining a new generation of addicted customers.

\section{SUMMARY AND CONCLUSION}

All smokers should be encouraged to quit and to use e-cigarettes when they are the most appropriate choice for one's situation. Research toward uncovering the risks of e-cigarette use is aligned with optimizing harm reduction and with encouraging smoking cessation. There has been great recent progress in addressing the challenges inherent in e-cigarette chemical and analytical research. This has resulted in heightened understanding of the origins of interlaboratory variability in reporting toxin levels. However, much still needs to be accomplished. As devices continue to evolve, new trends need to be quickly revealed. For example, many newer e-cigarette models can exhibit improved wicking efficiency and 
airflow, thereby producing relatively fewer thermal degradation products. However, improved wicking also leads to higher doses of solvents, flavoring molecules, nicotine, and other ingredients. Under the guise of harm reduction, manufacturers are creating high-dose, flavored nicotine products of great appeal to children and adolescents. Evidence continues to mount, based largely on unbiased investigations of e-cigarette chemistry, that e-cigarettes are not nearly as harmless as advertised.

\section{ACKNOWLEDGMENTS}

The author thanks the US National Institutes of Health (NIH) and the US Food and Drug Administration (FDA) for their support via award R01ES025257. The content herein is solely the responsibility of the author and does not necessarily represent the views of the NIH or the FDA.

\section{LITERATURE CITED}

1. Proctor RN. 2012 The history of the discovery of the cigarette-lung cancer link: evidentiary traditions, corporate denial, global toll. Tob. Control 21:87-91 [PubMed: 22345227]

2. Huang J, Duan Z, Kwok J, Binns S, Vera LE, et al. 2018 Vaping versus JUULing: how the extraordinary growth and marketing of JUUL transformed the US retail e-cigarette market. Tob. Control, 10.1136/tobaccocontrol-2018-054382

3. Barrington-Trimis JL, Leventhal AM. 2018 Adolescents' use of "pod mod" e-cigarettes—urgent concerns. N. Engl. J. Med. 379:1099-102 [PubMed: 30134127]

4. Russell M 1976 Low-tar medium-nicotine cigarettes: a new approach to safer smoking. Br. Med. J. 1:1430-33 [PubMed: 953530]

5. Peeters S, Gilmore AB. 2014 Understanding the emergence of the tobacco industry's use of the term tobacco harm reduction in order to inform public health policy. Tob. Control 24:182-89 [PubMed: 24457543]

6. Grandjean P 2016 Paracelsus revisited: the dose concept in a complex world. Basic Clin. Bharm. Toxicol. 119:126-32

7. Bhatnagar A 2016 E-cigarettes and cardiovascular disease risk: evaluation of evidence, policy implications, and recommendations. Cum Cardiovasc. Risk Rep. 10:24

8. Lisko JG, Tran H, Stanfill SB, Blount BC, Watson CH. 2015 Chemical composition and evaluation of nicotine, tobacco alkaloids, $\mathrm{pH}$, and selected flavors in e-cigarette cartridges and refill solutions. Nicotine Tob. Res. 17:1270-78 [PubMed: 25636907]

9. Oh J-A, Shin H-S. 2014 Identification and quantification of several contaminated compounds in replacement liquids of electronic cigarettes by gas chromatography-mass spectrometry. J. Chromatogr. Sci. 53:841-48 [PubMed: 25404560]

10. Hutzler C, Paschke M, Kruschinski S, Henkler F, Hahn J, Luch A. 2014 Chemical hazards present in liquids and vapors of electronic cigarettes. Arch. Toxicol. 88:1295-308 [PubMed: 24958024]

11. Hallaghan J 2015 The safety assessment and regulatory authority to use flavors: focus on ecigarettes. https://www.fernaflavor.org/member-update/safety-assessment-and-regulatoryauthority-use-flavors-focus-e-cigarettes

12. Korzun T, Lazurko M, Munhenzva I, Barsanti KC, Huang Y, et al. 2018 E-cigarette airflow rate modulates toxicant profiles and can lead to concerning levels of solvent consumption. ACS Omega 3:30-36 [PubMed: 29399647]

13. Behar RZ, Luo WT, McWhirter KJ, Pankow JF, Talbot P. 2018 Analytical and toxicological evaluation of flavor chemicals in electronic cigarette refill fluids. Sci. Rep. 8:8288 [PubMed: 29844439]

14. Fetterman JL, Weisbrod RM, Feng B, Bastin R, Tuttle ST, et al. 2018 Flavorings in tobacco products induce endothelial cell dysfunction. Anerioscler. Thromb. Vase. Biol. 38:1607-15

15. Sassano MF, Davis ES, Keating JE, Zorn BT, Kochar TK, et al. 2018 Evaluation of e-liquid toxicity using an open-source high-throughput screening assay. PLOS Biol. 16:e2003904 [PubMed: 29584716] 
16. Glantz SA, Bareham DW. 2018 E-cigarettes: use, effects on smoking, risks, and policy implications. Annu. Rev. Public Health 39:215-35 [PubMed: 29323609]

17. Abrams DB, Glasser AM, Pearson JL, Villanti AC, Collins LK, Niaura RS. 2018 Harm minimization and tobacco control: reframing societal views of nicotine use to rapidly save lives. Annu. Rev. Public Health 39:193-213 [PubMed: 29323611]

18. US Food Drug Admin. 2018 Statement from FDA Commissioner Scott Gottlieb, M.D., on new steps to address epidemic of youth e-cigarette use.Press Release,918 https://www.fda.gov/ NewsEvents/Newsroom/PressAnnouncements/ucm620185.htm

19. Wang TW, Gentzke A, Sharapova S, Cullen KA, Ambrose BK, Jamal A. 2018 Tobacco product use among middle and high school students-United States, 2011-2017. Morb. Moral. Wkly. Rep. 67:629-33

20. Wild CP, Kleinjans J. 2003 Children and increased susceptibility to environmental carcinogens: evidence or empathy? Cancer Epidemiol. Biomark. Prev. 12:1389-94

21. Rubinstein ML, Deluechi K, Benowitz NL, Ramo DE. 2018 Adolescent exposure to toxic volatile organic chemicals from e-cigarettes. Pediatrics 141 :e20173557 [PubMed: 29507165]

22. Bunnell RE, Agaku IT, Arrazola RA, Apelberg BJ, Caraballo RS, et al. 2015 Intentions to smoke cigarettes among never-smoking US middle and high school electronic cigarette users: National Youth Tobacco Survey, 2011-2013. Nicotine Fob. Res. 17:228-35

23. USA Cig. 2013 The electric cigarette: frequently asked questions. https://web.archive.org/web/ 20130403100952/http://www.usacig.com/faq.aspx

24. De Andrade M, Hastings G, Angus K. 2013 Promotion of electronic cigarettes: tobacco marketing reinvented? BMJ 347:f7473

25. Jensen RP, Strongin RM, Peyton DH. 2017 Solvent chemistry in the electronic cigarette reaction vessel. Set. Rep. 7:42549

26. Nef JU. 1904 Dissociation processes in the glycol-glycerine sequence. Justus Liebigs Ann. Chem. 335:191-245

27. Chen WH, Wang P, Ito K, Fowles J, Shusterman D, et al. 2018 Measurement of heating coil temperature for e-cigarettes with a "top-coil" clearomizer. PLOS ONE 13:e0195925 [PubMed: 29672571]

28. Eddingsaas N, Pagano T, Cummings C, Rahman I, Robinson R, Hensel E. 2018 Qualitative analysis of e-liquid emissions as a function of flavor additives using two aerosol capture methods. Int.J. Environ. Res. Public Health 15:323

29. Bansal V, Kim K-H. 2016 Review on quantitation methods for hazardous pollutants released by ecigarette (EC) smoking. TrAC Trends Anal. Chem. 78:120-33

30. Malek N, Nakkash R, Talih S, Lotfi T, Salman R, et al. 2018 A transdisciplinary approach to understanding characteristics of electronic cigarettes. Tob. Regul. Sci. 4:47-72

31. Zhao J, Nelson J, Dada O, Pyrgiotakis G, Kavouras IG, Demokritou P. 2018 Assessing electronic cigarette emissions: linking physico-chemical properties to product brand, e-liquid flavoring additives, operational voltage and user puffing patterns. Inhal. Toxicol. 30:78-88 [PubMed: 29564955]

32. Zhao JY, Zhang YP, Sisler JD, Shaffer J, Leonard SS, et al. 2018 Assessment of reactive oxygen species generated by electronic cigarettes using acellular and cellular approaches. J. Hazard. Mater. 344:549-57 [PubMed: 29102637]

33. Gillman I, Kistler K, Stewart E, Paolantonio A. 2016 Effect of variable power levels on the yield of total aerosol mass and formation of aldehydes in e-cigarette aerosols. Regul. Toxicol. Phatmacol. 75:58-65

34. Vreeke S, Korzun T, Luo W, Jensen RP, Peyton DH, Strongin RM. 2018 Dihydroxyacetone levels in electronic cigarettes: wick temperature and toxin formation. Aerosol Sci. Technol. 52:370-76 [PubMed: 30686853]

35. Talih S, Salmon R, Karaoghlanian N, El-Hellani A, Saliba N, et al. 2017 "Juice monsters": subohm vaping and toxic volatile aldehyde emissions. Chem. Res. Toxicol. 30:1791-93 [PubMed: 28937746]

36. Pisinger C, Døssing M. 2014 A systematic review of health effects of electronic cigarettes. Prev. Med. 69:248-60 [PubMed: 25456810] 
37. Farsalinos KE, Gillman G. 2018 Carbonyl emissions in e-cigarette aerosol: a systematic review and methodological considerations. Front. Physiol. 8:1119 [PubMed: 29375395]

38. Farsalinos KE, Kistler KA, Pennington A, Spyrou A, Kouretas D, Gillman G. 2018 Aldehyde levels in e-cigarette aerosol: findings from a replication study and from use of a new-generation device. Food Chem. Toxicol. $111: 64-70$ [PubMed: 29109042]

39. Farsalinos KE, Voudris V, Poulas K. 2015 E-cigarettes generate high levels of aldehydes only in 'dry puff'conditions. Addiction 110:1352-56 [PubMed: 25996087]

40. Farsalinos KE, Voudris V, Spyrou A, Poulas K. 2017 E-cigarettes emit very high formaldehyde levels only in conditions that are aversive to users: a replication study under verified realistic use conditions. Food Chem. Toxicol. 109:90-94 [PubMed: 28864295]

41. Shihadeh A, Talih S, Eissenberg T. 2015 Unjustified conclusions. Addiction 110:1862 [PubMed: 26395274]

42. Khlystov A, Samburova V. 2017 Response to comment on "Flavoring compounds dominate toxic aldehyde production during e cigarette vaping.” Environ. Sci. Technol. 51:2493-94 [PubMed: 28170247]

43. Salamanca JC, Meehan-A trash J, Vreeke S, Escobedo JO, Peyton DH, Strongin RM. 2018 Ecigarettes can emit formaldehyde at high levels under conditions that have been reported to be nonaverse to users. Sci. Rep. 8:7559 [PubMed: 29765089]

44. Saliba NA, El Hellani A, Honein E, Salman R, Talih S, et al. 2018 Surface chemistry of electronic cigarette electrical heating coils: effects of metal type on propylene glycol thermal decomposition. J. Anal. Appl. Pyrolysis 134:520-25 [PubMed: 30906089]

45. Khlystov A, Samburova V. 2016 Flavoring compounds dominate toxic aldehyde production during e-cigarette vaping. Environ. Sci. Technol. 50:13080-85 [PubMed: 27934275]

46. Klager S, Vallarino J, MacNaughton P, Christiani DC, Lu Q, Allen JG. 2017 Flavoring chemicals and aldehydes in e-cigarette emissions. Environ. Sci. Technol. 51:10806-13 [PubMed: 28817267]

47. Soussy S, Ahmad E-H, Baalbaki R, Salman R, Shihadeh A, Saliba NA. 2016 Detection of 5hydroxymethylfurfural and furfural in the aerosol of electronic cigarettes. Tob. Control 25:ii88-93 [PubMed: 27798321]

48. Vreeke S, Peyton DH, Strongin RM. 2018 Triaeetin enhances levels of acrolein, for maldehyde hemiac-etals, and acetaldehyde in electronic cigarette aerosols. ACS Omega 3:7165-70 [PubMed: 30087908]

49. Farsalinos K, Gillman G, Kistler K, Yannovits N. 2017 Comment on "flavoring compounds dominate toxic aldehyde production during e cigarette vaping.” Environ. Sci. Technol. 51:2491-92 [PubMed: 28170231]

50. Samburova V, Bhattarai C, Strickland M, Darrow L, Angermann J, et al. 2018 Aldehydes in exhaled breath during e-cigarette vaping: pilot study results. Toxics 6:46

51. Qu Y, Kim K-H, Szulejko JE. 2018 The effect of flavor content in e-liquids on e-cigarette emissions of carbonyl compounds. Environ. Res. 166:3241-33

52. Bitzer ZT, Goel R, Reilly SM, Elias RJ, Silakov A, et al. 2018 Effect of flavoring chemicals on free radical formation in electronic cigarette aerosols. Free Radic. Biol. Med. 120:72-79 [PubMed: 29548792]

53. Pankow JF. 2017 Calculating compound dependent gas-droplet distributions in aerosols of propylene glycol and glycerol from electronic cigarettes. J. Aerosol Sci. 107:9-13

54. Oldham MJ, Zhang J, Rusyniak MJ, Kane DB, Gardner WP. 2018 Particle size distribution of selected electronic nicotine delivery system products. Food Chem. Toxicol. 113:236-40 [PubMed: 29408542]

55. Mikheev VB, Brinkman MC, Granville CA, Gordon SM, Clark PI. 2016 Real-time measurement of electronic cigarette aerosol size distribution and metals content analysis. Nicotine Tob. Res. 18:1895-902 [PubMed: 27146638]

56. Kosmider L, Spindle TR, Gawron M, Sobczak A, Goniewicz ML. 2018 Nicotine emissions from electronic cigarettes: individual and interactive effects of propylene glycol to vegetable glycerin composition and device power output. Food Chem. Toxicol. 115:302-5 [PubMed: 29572013]

57. Spindle TR, Talih S, Hiler MM, Karaoghlanian N, Halquist MS, et al. 2018 Effects of electronic cigarette liquid solvents propylene glycol and vegetable glycerin on user nicotine delivery, heart 
rate, subjective effects, and puff topography. Drug Alcohol Depend. 188:193-99 [PubMed: 29778773]

58. Duell AK, Pankow JF, Peyton DH. 2018 Free-base nicotine determination in electronic cigarette liquids by ${ }^{1}$ H NMR spectroscopy. Chem. Res. Toxicol. 31:431-34 [PubMed: 29775302]

59. Koval R 2017 Monitoring the future reveals good and bad news underscoring need for education and regulation. Tmth Initiative, $1214 \mathrm{https}$ ://truthinitiative.org/news/monitoring-future-revealsgood-and-bad-news-underscoring-need-education-and-regulation 


\section{PREFERRED METHODS OF VAPING}

Mouth-to-lung (MTL) and direct lung inhalation (DLI) are terms that describe two of the more popular ways to use e-cigarettes. MTL vaping is more similar to cigarette or cigar smoking, wherein one initially draws the aerosol into the mouth before inhaling into the lungs. DLI involves inhalation directly into the lungs. MTL is associated with lowerpower e-cigarettes, tighter airflow, and smaller aerosol volumes. DLI is associated with lower-resistance (sub-ohm) heating coils, higher power, and less restricted airflow. DLI, along with higher proportions of GL to PG, is preferred by users that want to produce large aerosol clouds. Variations in user topography, such as MTL or DLI vaping, can impact the aerosol concentrations of toxic by-products (12). 


\section{GLYCEROL, PROPYLENE GLYCOL, AND THE HISTORY OF CHEMISTRY}

The first known synthesis of glycerol was reported by the Swiss chemist Carl Wilhelm Scheele in 1779. He found that it was thermally unstable upon simple distillation. By the mid-nineteenth century, acrolein and acetic acid had been identified as glycerol degradation products. Charles-Adolphe Wurtz synthesized propylene glycol in 1859 . Much of our current understanding of glycerol and propylene glycol chemistry, as shown in Figures 3 and 4, for example, is attributable to the American chemist John Nef. In 1904 (26), he reported that heating glycerol led to the production of glycidol, hydroxyacetone, acetaldehyde, formaldehyde, acrolein, 3-hydroxypropanal, and several acetals. Nef also reported the thermal conversion of propylene glycol to propanal (25). 


\section{SUMMARY POINTS}

1. The study of e-cigarette chemistry supports the fact that they are not as harmless as initially claimed. However, this should not encourage continued smoking.

2. Progress has been made in addressing the wide interlaboratory variability in reported levels of e-cigarette aerosol toxins. The dynamic nature of the field is an ongoing source of new challenges.

3. The major components of e-liquid, the organic solvents PG and GL, can undergo thermal degradation via dehydration and oxidation reactions. This leads to a variety of toxins at levels that are highly dependent on heat and wicking efficiency.

4. Flavoring additives can also undergo a variety of chemical reactions during aerosolization that elevate toxic carbonyl levels in aerosols.

5. Unrealistic experimental conditions do not explain all instances of the formation of elevated levels of toxins during e-cigarette usage, as claimed by industry proponents. The evidence shows that users cannot always reliably self-regulate toxin intake, and that toxic carbonyls can form at temperatures well below those associated with sensorially detectable dry puffs.

6. Newer generation e-cigarette devices can operate at higher power and with greater wicking efficiency. This can inhibit thermal degradation reactions but results in elevated doses of aerosol contents such as solvents, flavorings, and any impurities.

7. Pod-mod e-cigarettes such as JUULs contain relatively high levels of protonated nicotine salts that, along with flavorings, render them highly addictive and sensorially attractive to young people. High levels of protonated nicotine in JUULs has been confirmed via a new technique that avoids the use of solvents that disrupt the measurement. 


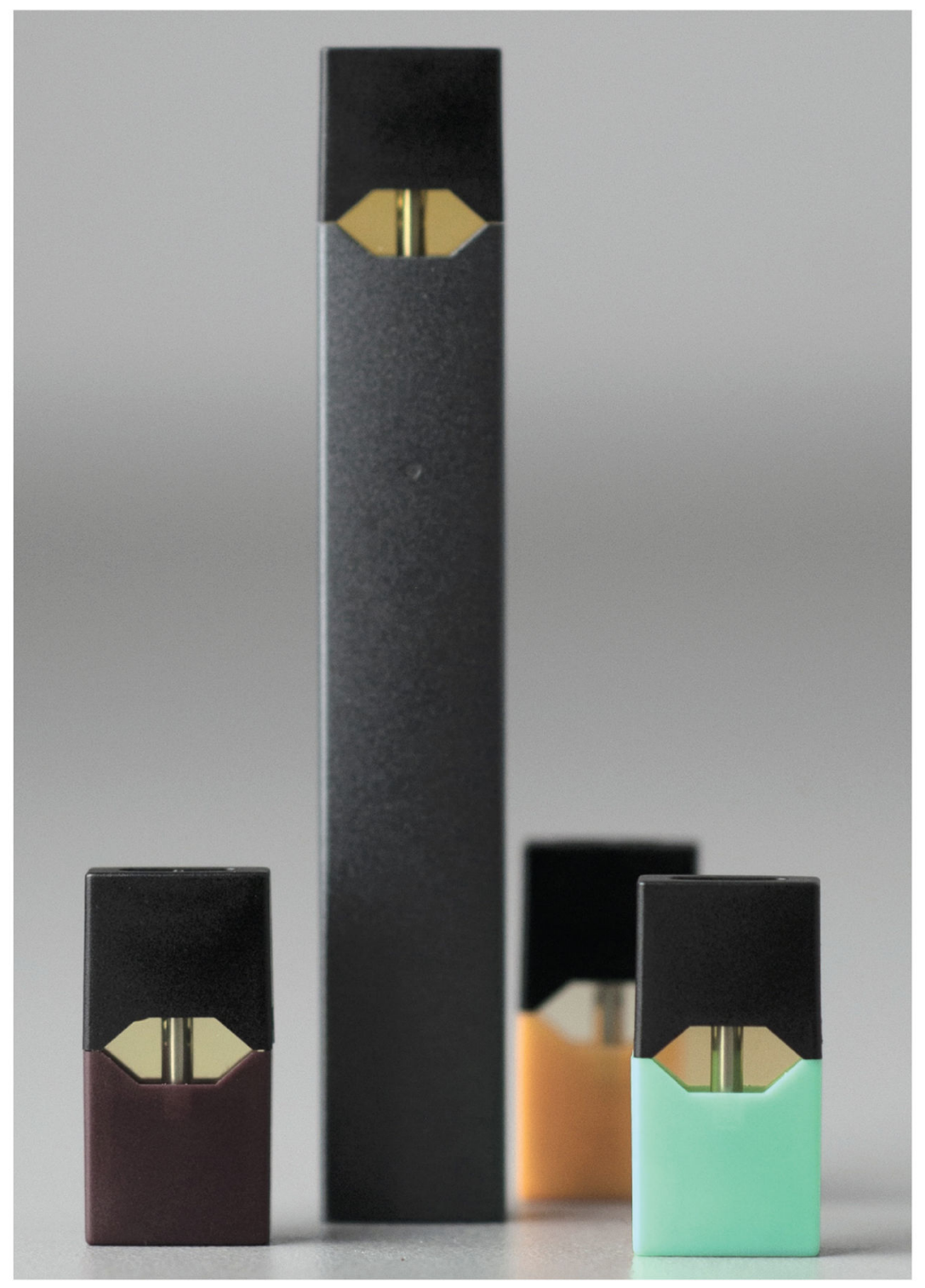

Figure 1.

A Juul electronic cigarette, with four pods (one loaded and three next to it). Juul e-cigarette usage is prevalent among teens, prompting the US Food and Drug Administration to term the situation an epidemic. Adapted fromWikipedia Commons under the terms of the Creative Commons Attribution (CC BY-SA) License, https://creativecommons.org/ licenses/by-sa/4.0. 


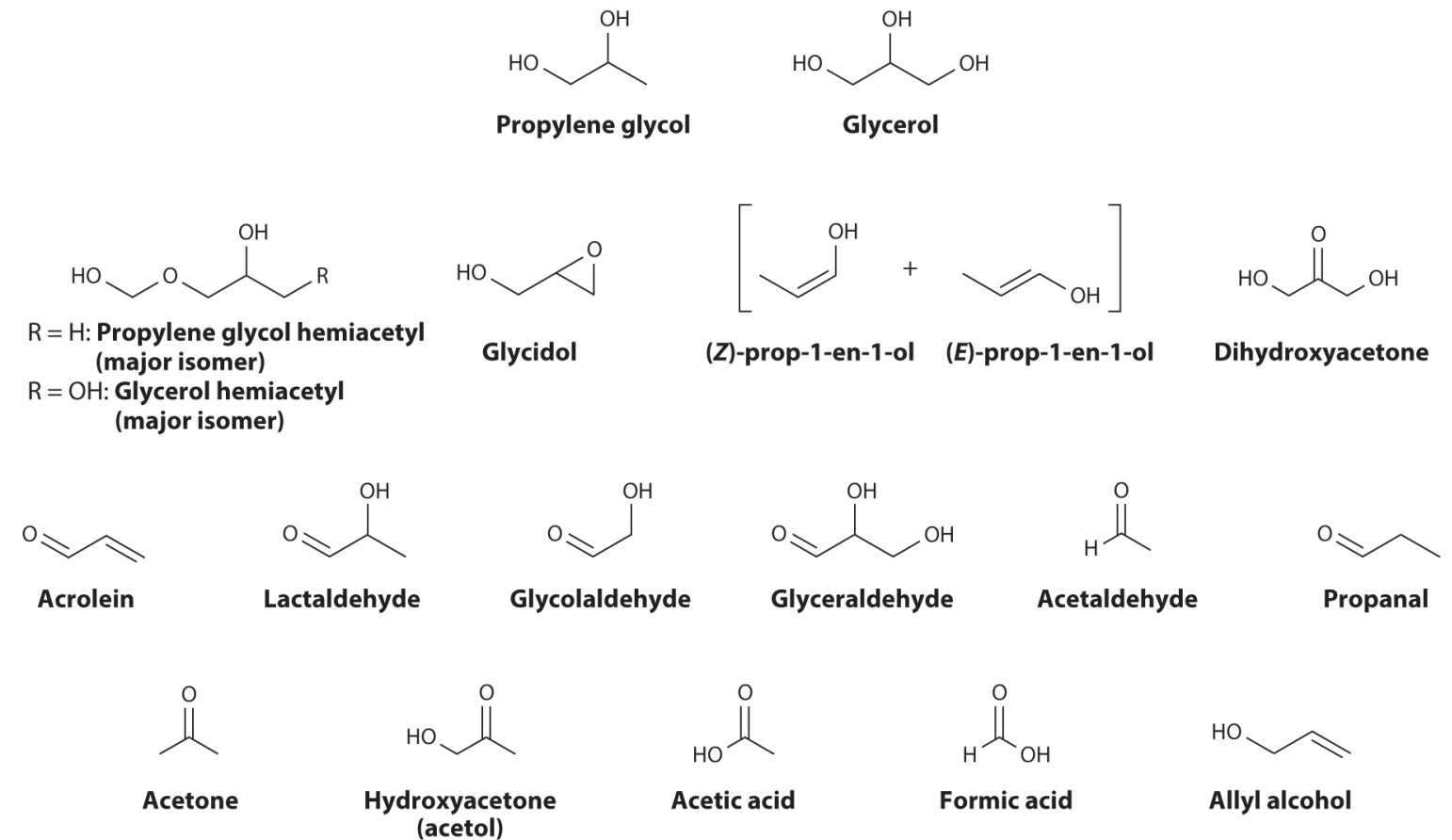

Figure 2.

Molecules determined by nuclear magnetic resonance in e-cigarette aerosols. They include known risk factors for cardiovascular disease at reported detection levels. The pathways leading to their formation are shown in Figures 3 and 4. Adapted from Reference 25 under the terms of the Creative Commons Attribution 4.0 International License, http:// creativecommons.org/licenses/by/4.0. 


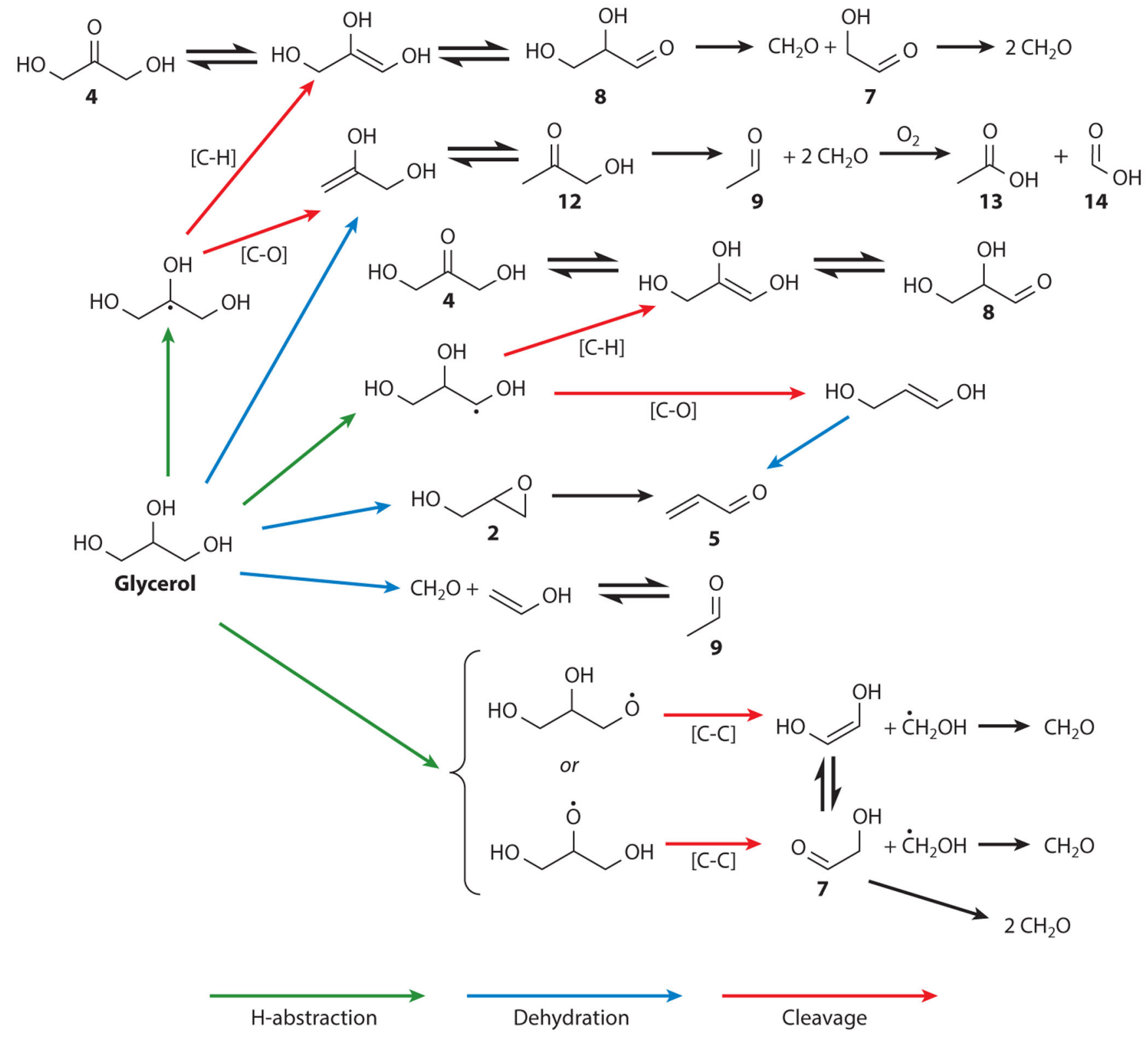

Figure 3.

Decomposition pathways of glycerol in e-cigarettes. The most prevalent reaction mechanisms involve oxidation and dehydration. Adapted from Reference 25 under the terms of the Creative Commons Attribution 4.0 International License, http://creativecommons.org/ licenses/by/4.0. 


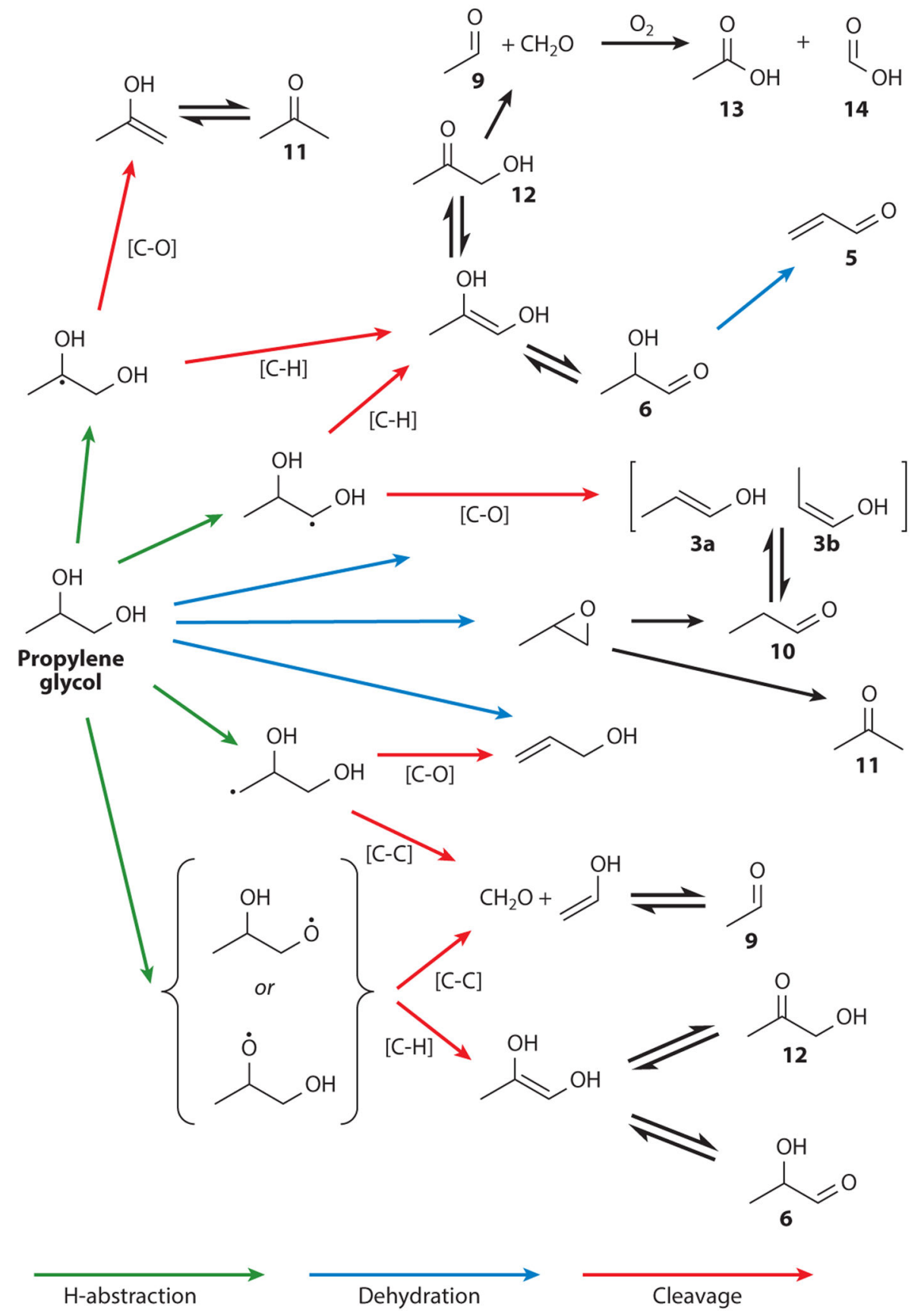

Figure 4.

Decomposition pathways of propylene glycol in e-cigarettes. As in the case of glycerol (Figure 3), the most prevalent reaction mechanisms involve oxidation and dehydration. Adapted from Reference 25 under the terms of the Creative Commons Attribution 4.0 International License, http://creativecommons.org/licenses/by/4.0. 


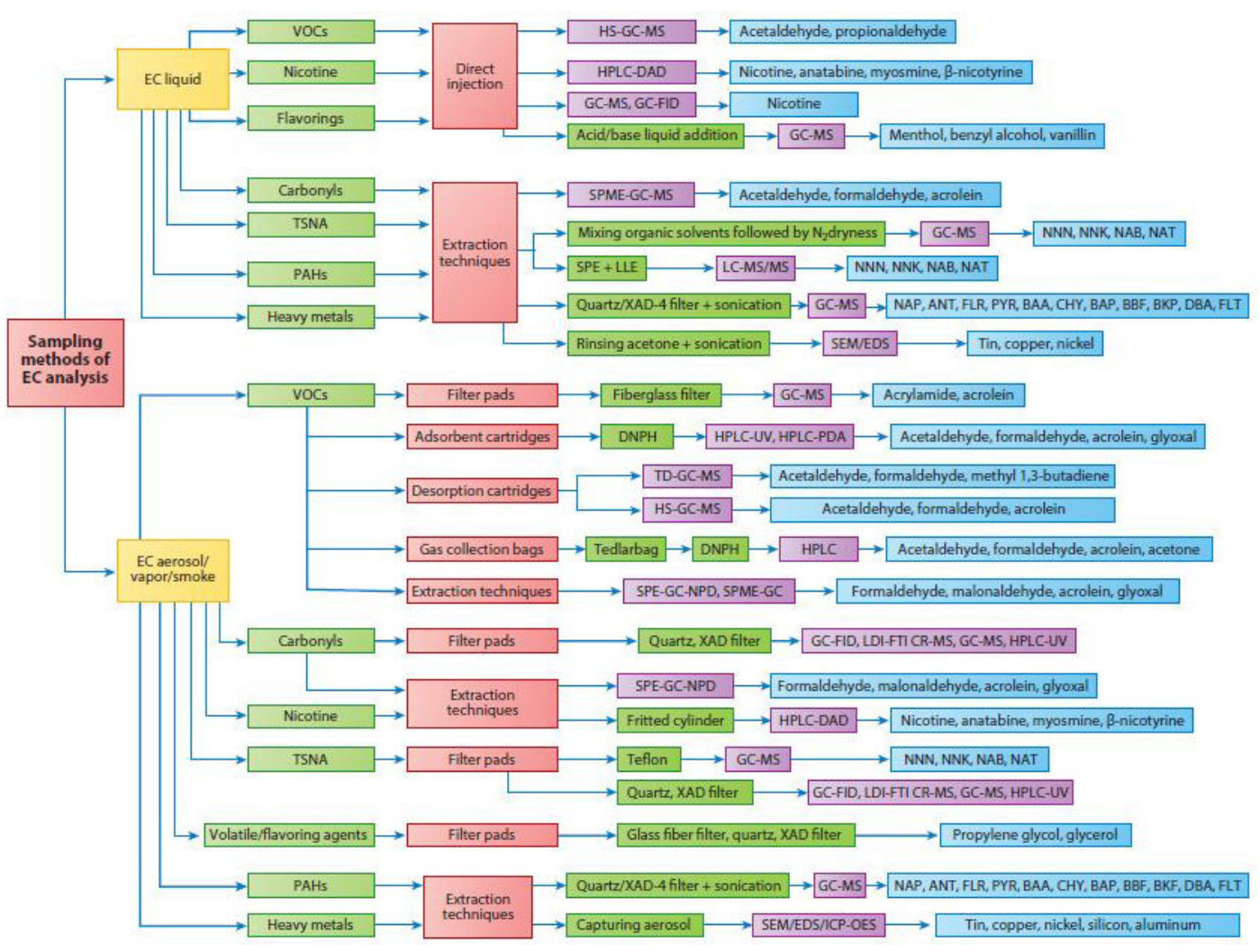

Figure 5.

Examples of sampling methods for EC analysis. The boxes depict the following: analyte class (light green), sample collection (pink), pretreatment (dark green), analytical technique (purple), and specific analytes detected (blue). Adapted with permission from Reference 29. Copyright 2016, Elsevier. Abbreviations: ANT, anthracene; BAA, benz[a]anthracene; BAP, benzo[a]pyrene; BBF, benzo[ $b]$ fluoranthene; BKP, benzo[ $k]$ fluoranthene; $\mathrm{CHY}$, chrysene; $\mathrm{CR}$, cyclotron resonance; DAD, diode array detection; DBA, dibenz[ $a, b]$ anthracene; DNPH, dinitrophenylhydrazine; EC, electronic cigarette; EDS, energy-dispersive X-ray spectroscopy; FID, flame ionization detection; FLR, fluorine; FLT, fluoranthene; FTI, Fourier transform ion; GC, gas chromatography; HPLC, high-pressure liquid chromatography; HS, head space; ICP-OES, inductively coupled plasma optical emission spectrometry; LDI, laser desorption/ionization; LLE, liquid-liquid extraction; MS, mass spectrometry; MS/MS, tandem MS; NAB, nitrosoanabasine; NAP, naphthalene; NAT, N' nitrosoanatabine; NNK, nicotine-derived nitrosamine ketone; $\mathrm{NNN}=\mathrm{N}$-nitrosonornicotine; NPD, nitrogen phosphorous detection; PAH, polycyclic aromatic hydrocarbon; PYR, pyrene; SEM, scanning electron microscopy; SPE, solid-phase extraction; SPME, solidphase microextraction; TD, thermal desorption; TSNA, tobacco-specific nitrosamine; VOC, volatile organic compound. 
Puffing of EC generates smoke

Gaseous suspended particles

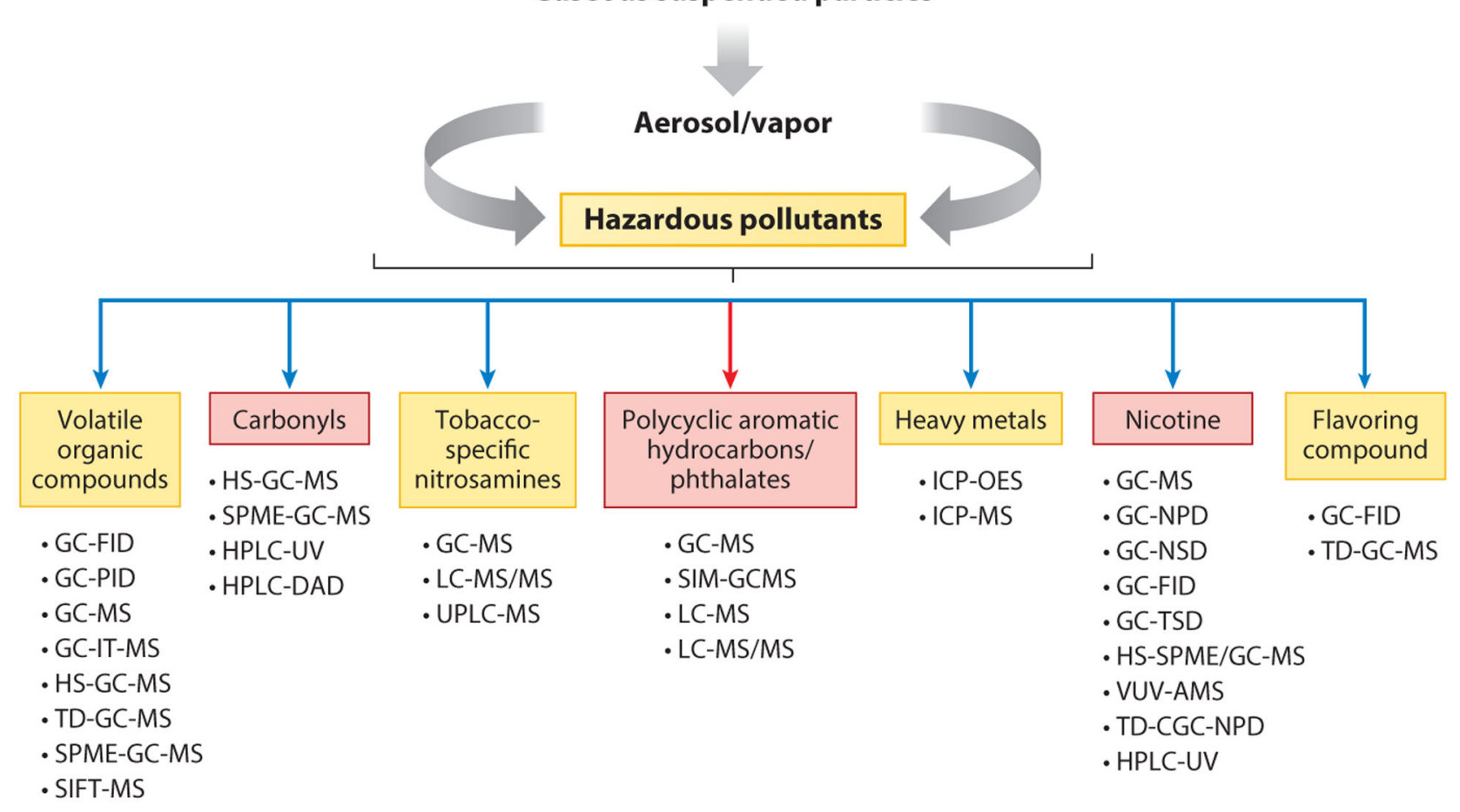

Figure 6.

Examples of analytical methods for EC analysis. Adapted with permission from Reference 29. Copyright 2016, Elsevier. Abbreviations: AMS, aerosol mass spectrometry; CGC, capillary gas chromatography; DAD, diode array detection; EC, electronic cigarette; FID, flame ionization detection; GC, gas chromatography; HPLC, high-pressure liquid chromatography; HS, head space; ICP-OES, inductively coupled plasma optical emission spectrometry; IT, ion trap; MS, mass spectrometry; MS/MS, tandem MS; NPD, nitrogen phosphorous detection; NSD, nitrogen selective detection; PID, photoionization detection; SIFT, selected ion flow tube; SIM, selected ion monitoring; SPME, solid-phase microextraction; TD, thermal desorption; TSD, thermionic specific detection; UP, ultraperformance; VUV, vacuum ultraviolet. 


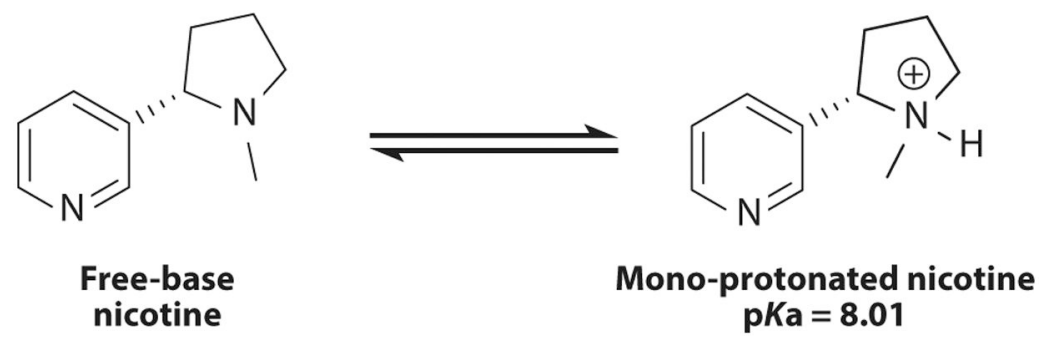

Figure 7.

The most abundant protonation states of nicotine. The $\mathrm{p} K_{\mathrm{a}}$ value corresponds to $25^{\circ} \mathrm{C}$ in $\mathrm{H}_{2} \mathrm{O}$. Protonated nicotine is less harsh and can have greater potential for addiction. Protonated nicotine is delivered to the lungs in the aerosol particulate phase. 


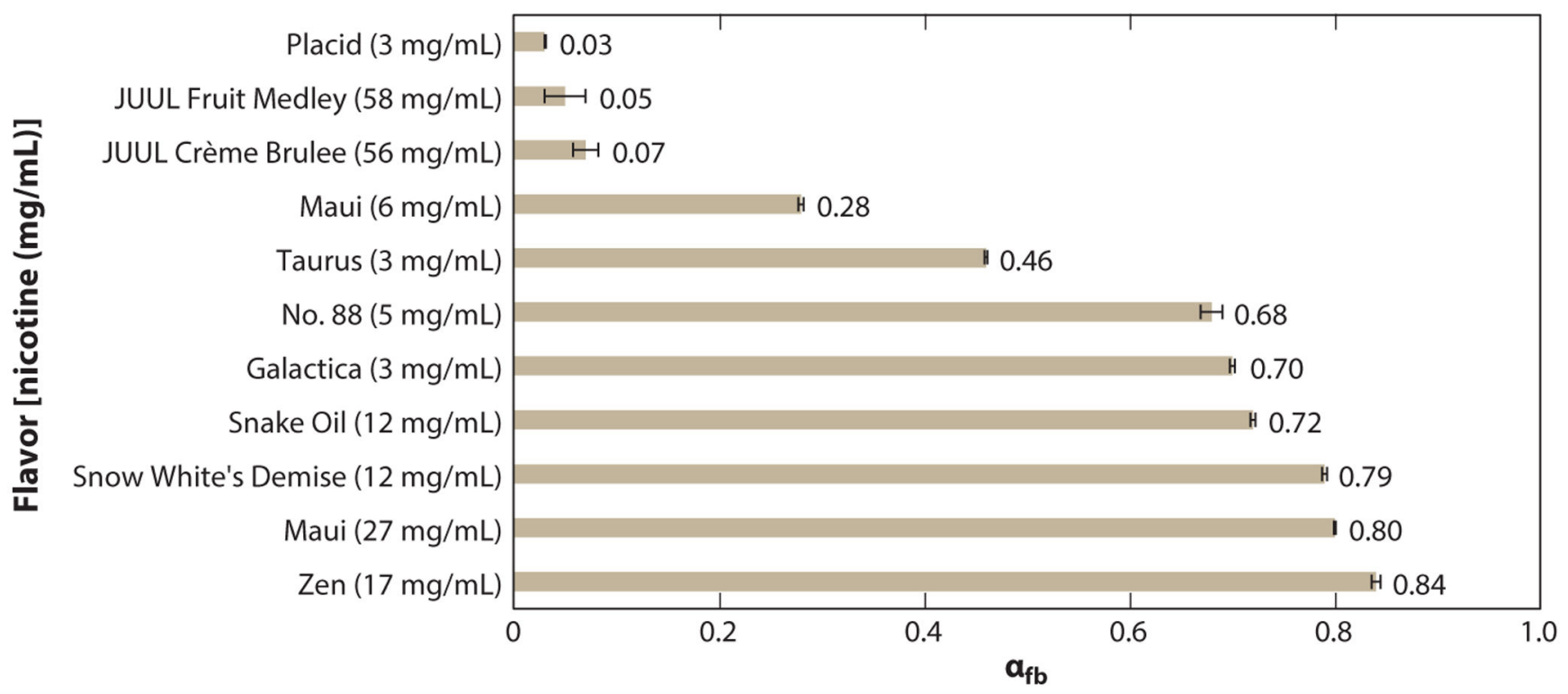

Figure 8.

Commercial e-liquid flavors and their nicotine content. The $\mathrm{x}$-axis shows the free-base (fb) nicotine fraction. A low ratio of free-base to protonated nicotine dampens aerosol harshness and thus may enhance the popularity and addiction potential of e-cigarettes such as Juuls with teens and pre-teens. Adapted with permission from Reference 58. Copyright 2018, American Chemical Society. 